\title{
Rubrics in a Secondary Mathematics Class
}

\author{
Maria Jesus Gallego-Arrufat ${ }^{1}$, Maha Dandis ${ }^{2}$ \\ ${ }^{1} \mathrm{PhD}$ Education. Associate Professor, University of Granada, Spain \\ ${ }^{2} \mathrm{PhD}$ International, Educational Sciences. Al-Quds University \& University of Granada
}

\begin{abstract}
This paper aims to share the study of integrating a rubric as an assessment for learning tool in a secondary mathematics classroom in Spain. More precisely, this study intends to examine the viewpoint of a Spanish teacher regarding the benefits and difficulties of using rubrics as an assessment for learning tool. The intent of this article is to motivate secondary mathematics teachers to use rubrics in their classes. In addition, this article aims to contribute to the limited literature that pertains to the use of rubrics in secondary education. The results indicated that rubrics have the potential to enhance students' learning and teacher's work. Using the rubric made the students an active part in the learning process since they knew what is expected from them and worked hard to achieve the required level. In addition, using the rubric allowed the teacher to check on daily bases the level of understanding for all students. On the other hand, the rubric consumed a lot of time and effort from the teacher and her students because the rubric was a new method for them. The students argued that using the rubric is difficult because it requires a lot of details and because they are not used to use mathematical language to explain every step in problem solving.
\end{abstract}

Keywords: Secondary Education, Assessment Rubrics, Mathematics Instruction, Peer

Evaluation

\section{INTRODUCTION}

With the rapid technological development, the need for students who have cognitive skills such as problem solving, critical thinking, and ability to analyse and present data orally and in a written format has increased (Dochy, 2001). Many of assessment modes and instruments used currently in mathematics education fail to provide valid insight into what students know, understand, and can achieve. No single assessment instrument is sufficient for this purpose; balanced sets of instruments are needed reference. Teachers need assessment techniques that focus on assessing what students know as well as what they do not know. Therefore, we need to use multiple and complex assessment tools including written, oral, and demonstration's formats. Alternative assessment tools, such as rubrics, concept maps, portfolios, students' journals, self-assessments, and peer/group assessments are necessary to determine what students actually know and where they are in the learning process (Anderson, 1998; Birgin, 2011).

Alternative assessment is based on the constructivism psychology Piaget's and Vygotsky emphasize the importance of developing students' ability to construct and to supply 
responses rather than selecting or choosing them (Dogan, 2011). Johnsen (1996) added that the purposes of alternative assessment are to motivate students to do their best work, to raise students' self-confidence and self-concept, and to demonstrate improvement in students' quality of work overtime. Alternative assessment demands clear understanding from students about what they expect to do and learn. In partnership with their instructors, students monitor and adjust their own progress and play a role in communicating evidence of their own learning (Stiggins, 2005).

Goodrich (1997) listed five reasons for using rubrics as an alternative assessment tool. First, rubrics are used to make the expectations of the teacher clear. Second, they help students to become more thoughtful judges of the quality of their own and others' work. Third, rubrics reduce the amount of time teachers spend evaluating student work. Fourth, they allow teachers to accommodate heterogeneous classes. Finally, rubrics provide an easy way to explain student evaluation to parents.

Stevens and Levi (2005) defined a rubric as "a scoring tool that lays out the specific expectations for an assignment, rubrics divided an assignment in to its component parts and provide detailed description of what constitutes acceptable or unacceptable level of performance for each of these parts". Mertler (2001) added that any rubric has three features: evaluative criteria, quality definitions, and scoring strategy.

The scoring strategy could be either analytic or holistic. A holistic rubric obligates the teacher to score the overall performance as a whole, without judging the constituents separately. So, in holistic rubrics general uncategorized descriptions of overall quality of performance are provided (McGatha \& Darcy, 2010; Popham, 1997). On the other hand, analytical rubrics require the teacher to score every process or to separate student's performance into parts to obtain the total score. In analytical rubrics specific, highly categorized and extensive descriptions of each level of quality of performance for each criterion are provided (McGatha \& Darcy, 2010).

Pajares (1992) pointed that the teacher is the key in any educational reform. Therefore, teachers' perception should be taken in consideration before integrating any alternative assessment. "If the teacher accept or have positive perceptions on alternative assessment, they will surely support the assessment and make sure the alternative assessment succeeded in reality" (Nasri et al., 2010, 40). Therefore, according to Wilson (2005), if teachers do not see the potential of using rubrics in changing the approach of teaching and learning, the effect of rubrics in assessment for learning will be limited.

Throughout an extensive literature review that focused on integrating rubrics in secondary mathematics classes in Spain, and on teachers' perspective about using rubrics on the teaching-learning process in mathematics classroom, we found very few studies about this topic. Therefore, this study aims to examine the viewpoints of Spanish teacher regarding the use of a rubric in secondary mathematics classrooms. Specifically, this study focuses on exploring the benefits and difficulties that faces a Spanish teacher and her students in using a rubric as an assessment for learning tool. We hope that the findings of the study would motivate and encourage teachers to use rubrics throughout the teachinglearning process in mathematics classrooms.

\section{METHOD}

This is a case-study qualitative research. A case study is an intensive analysis of an individual unit (e.g., a person, group, or event) stressing developmental factors in relation to context (Flyvbjerg, 2006). The case study research aims to explore an issue in a bound context or setting, using one or more cases within this context (Creswell, 2007). Thus, the case study is suitable for investigating the central phenomenon of this study, since the main aim of the researcher is to explore teacher's perspective about using a rubric as an assessment for learning tool in secondary schools context. A case study is an excellent choice for researchers who want to intensively and deeply examine an issue (Creswell, 2007). 


\section{Participants}

A mathematics teacher and her students $(\mathrm{N}=15)$ were drawn from a bilingual public school in Granada (Spain) participated in this study. The students who participated in the research were between 14 and 15 years old (Grade $3^{\circ}$ ESO or third year of Compulsory Secondary Education) ${ }^{1}$.

\section{Instrumentation}

One-on-one interviews and teacher's diary were used to collect information. The interview questions focused on the use of the rubric as an assessment for learning tool, and on the teacher's opinion about the benefits and the difficulties that faced them through using it. The teacher was interviewed three times. The interviews were made up by the researcher and were recorded using high quality digital tape-recorder after taking consent of the teacher for recording. The questions were formulated based on reviewing the literature and the teacher was interviewed two times after using the rubric.

Immediately following each interview the recordings were transcribed. The participants were provided with opportunity to make amendments to the transcript, or to withdraw any information that they were uncomfortable with. Upon receiving the transcripts back from the participants, the entire document was once again reviewed, and aliases replaced the names of the participants and the school.

The teacher was asked to write a reflective diary to describe her experience in using the rubric. Diaries as research instruments are suitable to collect detailed information about behaviour, events and other aspects of individuals' daily live (Corti, 1993).

Rubric. The rubric was adapted from Illinois' State Board of Education; it was chosen because it meets all the objectives of teaching Mathematics in the IES (or Junior High School) ${ }^{2}$. The rubric has three evaluation criteria as follows:

Mathematical knowledge: (Do you know it?) Knowledge of mathematical principles and concepts which result in a correct solution to a problem.

Strategic knowledge: (How do you plan?) Identification and use of important elements of the problem that represent and integrate concepts which yield the solution (e.g., models, diagrams, symbols, algorithms).

Explanation: (Can you explain it?) Written explanation of the rationales and steps of the solution process. A justification of each step is provided. Though important, the length of the response, grammar, and syntax are not the critical elements of this dimension.

The rubric was translated to Spanish language, modified, and reviewed by the teacher who was involved in the study, another Math teacher in the same school and two professors at the University of Granada.

\section{The process of rubric application in the classroom}

The teacher applied the rubric with her students in the absence of the researcher. Teachers' diary was the main source of information for the researcher about the process of rubric application. However, the researcher used to meet the teacher for further information. The teacher explained to her students that this new method of assessment would be used for research purposes. However, assessment by the rubric will affect their final grade because all exercises and exams of this unit will be assessed by the rubric. In

\footnotetext{
${ }^{1}$ E.S.O. = Educación Secundaria Obligatoria (Compulsory Secondary Education).

${ }^{2}$ I.E.S. $=$ Instituto de Educación Secundaria (Junior High School).
} 
addition, the teacher explained to her students that peer assessment would be used with the rubric.

Rubrics are new method of assessment to the participants, since Grade $3^{\circ}$ ESO students had never used rubrics in any classroom. Therefore, the teacher provided her students with proper training before the use of the rubric. The training included defining rubrics, explaining their main objectives and the detailed mechanism for using them.

The first time of using peer assessment by the rubric was on April 5, 2011. The teacher asked students to solve a problem, and then she asked each student to exchange his/her answer's sheet with the colleague next to them. The teacher asked each student to mark his/her colleague's answer sheet. Next, the teacher asked a student to solve the problem on blackboard and then the teacher marked the student's answer. The teacher gave the student's answer a mark of 5.75 out of 10 . The students consider this mark a low score. The teacher realised that the weakness point for the student was in the explanation. She commented: "The students are not accustomed to explain the strategies they used to solve the problem". Next, the teacher compared her marking with students' marking. The results were also low; no score exceeded 6 . After using the rubric to mark their colleague's answer, the students become panic. Their main fear was that this assessment method would affect their final grade negatively. However, the teacher calmed them through clarifying that the actual effect of assessing this unit on their final grade is going to be minimal. A student raised some doubts about this method. He said: "Assessment with this method demands more details for each answer. Thus, by this way, it is very difficult to solve more than two or three exercises". The teacher agreed and explained that the final exam for this unit will be shorter than usual. Another student added: "This form of assessment required studying the topic content day by day". The teacher also agreed with her student and clarified that this could be considered one of the advantages of this method. When the teacher announced that there will be no theoretical questions (memorizing questions) in the following exams. One student commented: "There is no need to use such questions since we have to put the theory in every question according to the rubric". The teacher commented that this could be considered another advantage of using the rubric in assessment, because students have always to revisit the theoretical topic material in order to answer according to the rubric.

On the following days, the students assessed various exercises using the rubric. The teacher commented "As we are getting deep in the content, solving all problems with all the required details becomes harder". Some students criticized the time of applying this new method of assessment. Their main arguing point was that they are in the third and final semester. According to them, it would have been better if this form of assessment is applied in the primary level and the grades $1^{\circ}$ and $2^{\circ}$ ESO. Students were sure that applying this method earlier can save training time, ensure that they master this type of assessment and reduce the negative effect on their final grade. The teacher agreed with her students. Some students wondered if they have to answer every question with all the written details on the rubric, and the teacher insisted that students should answer with the highest quality and clarity as possible. However, because the students were not accustomed to give more detailed and explanations, the teacher had to give them more examples of how accurately to answer every exercise. The teacher realized that regardless of the difficulties students had in explaining their answers properly, they enjoyed using peer assessment. The teacher commented: "The students enjoyed marking each other's work". In addition, the teacher realized that the students need to consult their books while solving each exercise. She wrote in her diary: "Although we have done many exercises using the rubric, the students need to go back to their books when they solve any problem. The student with this method study every day, not like before they only study before the exam".

On May 25th, the students had the unit exam. Some students were worried that the teacher may not provide them with the rubric, and that they have to memorise it. However, the teacher calms them down telling them that the exam sheet will include a copy of the rubric. The students faced no problems in applying the rubric using peer assessment because they are used to it. The students were worried about using peer assessment as the 
only source of marking; however, the teacher explained that she is going to assess the exam by herself and to compare their assessment with hers. The teacher wrote the key answers on the board, and asked students to mark according to it. She had some doubts about providing the students with the key answers; she wrote: "It would have been better if I let the students agree on the key answers alone without my direct supervision".

The teacher noted that many students had a good grade on Column 2 which evaluates the strategic knowledge, because they are used to be evaluated according to strategic knowledge. However, they had lower scores for Column (1) and Column (3), which evaluate mathematical knowledge and explanation quality respectively, because they were not used to provide many details as required by these columns. During the process of peer assessment, the teacher realized cases of conflict and dispute between students on marking. However, the teacher realized a positive side for their argument; the students understood that they have to give clearer, more concise and precise answers. The teacher noticed that the students assessed their peers critically. She commented: "Contrary to my fears that the students will over mark their partners, they were very critical when assessing the responses of their peers".

Reflecting on using rubric instead of the traditional methods of assessment, the teacher asserted that assessment using the rubric is useful. She argued that assessing by the rubric has an advantage over traditional assessment methods since it helped her to measure genuine understanding. According to her, some students might have correct answers according to traditional assessment methods however, they cannot explain these answers, explain them incorrectly or their explanation does not have any sense.

On the other hand the teacher confirmed that using the rubric have coasted her more time and effort than usual, because she is not used to it. However, according to her, more practice is needed from her and the students to master this way of assessment. The teacher pointed that the student's explanation reveals a problem in understanding. The student didn't understand that the correct answer is to substitute $\mathrm{X}$ which is dependent on $\mathrm{Y}$ (which is independent) and not the contrary. On the same answer sheet, the student wrote: "we subtract from four units a number multiplied by $(-2)$ ". The teacher pointed that the correct answer should be to subtract from four units a number multiplied by $(+2)$. The teacher pointed that a student wrote: "The fractional functions are defined for all the values that doesn't nullify the dominator, the function was $f(x)=(4-2 x) / 3$ the dominator can't be nullified, so I conclude that it's not fractional but its Polynomic function". The teacher wrote too: "I am very impressed that the student showed a reasoning ability, and knew how to express it very well". She added: "I would never notice that if I haven't used the rubric".

\section{Data analysis}

The analysis of the qualitative data was guided by the framework suggested by Miles and Huberman (1994) which involves data reduction, data display, and drawing conclusions and verification. Data reduction refers to the processes of selecting, simplifying, abstracting and transforming data into themes by coding (Creswell, 2007; Miles \& Huberman, 1994). These coded data were then organized and assembled into representations including mind maps and case summaries. This process is known as data display. The final stage in the data analysis was drawing conclusions and verification from the data.

\section{FINDINGS}

The teacher asserted that her student reacted positively when she first explained the rubric. The students were excited to know how their peers in the United States of America (USA) are assessed and evaluated. They raised some doubts about putting the rubric (grading matrix) into practice; they were worried about using mathematical language to explain in details the steps of problem solving in order to get the highest grade. The students are used solve problems with numbers not with words; it was difficult for them to 
use words instead of numbers. Although students reacted positively throughout the process of applying the rubric in assessment, they were also worried of using it in all math classes. They felt that assessment by the rubric demands more effort for them since they had to study more daily. In addition, they realized that they have to focus on understanding mathematical principals rather than memorizing them.

The following themes were extracted from teachers' interviews and diary:

\section{The advantages of using the rubric in assessment}

The teacher described using the rubric in assessment as a positive experience. According to the teacher, some of the advantages are:

Using the rubric in assessment enhanced students learning. According to the teacher, using the rubric enhanced the students learning because it demands detailed written explanation for every step in problem solving process. The teacher pointed that the students had to study the content thoroughly to reach genuine understanding in order to be able to explain every step they did. According to the teacher, this had a good effect on their learning since the students started to focus on understanding rather than memorizing. In addition, the teacher realized that the students' strategy for studying changed; instead of studying just the day before the exam, the rubric forced them to study daily. The teacher stressed that studying daily enhances learning since it accumulates understanding: "After using the rubric I have to say that assessment can be used to enhance learning and it is necessary to use different resources to improve educational outcomes for students".

Using the rubric in assessment made the students an active part in their learning. According to the teacher, using the rubric in assessment allowed the students to know what is expected from them to learn (teacher's expectations). In addition, she asserted that the rubric help students to understand the criteria of high quality work. So, students became aware of teacher's expectations in term of the learning objectives and the evaluation criteria for each quality level. This directs student to plan for their own learning to get higher marks. The teacher says: "A lot of students don't know what they had to do to pass the exam, now having this rubric with them every day also in the exam, they become more aware of what they have to do, and the student who gets zero he know that he didn't do anything".

Moreover, the teacher clarified that using the rubric in assessment help the students to evaluate their level of understanding; they became aware of what they know and what they do not know. "I think that the rubric is a great method as the students participate in the evaluation process; it obliged them to enhance their work, at least the student become aware of what they know and what they don't know".

Therefore, the teacher supported using the rubric in assessment since it makes the students an active part in the teaching-learning process.

Using the rubric in assessment enhanced the teacher's work. According to the teacher, using the rubric in assessment did not only enhance students' performance but also improves teacher's work from many facets. First, assessment by the rubric provided the teacher with accurate data about the students' level of understanding. Second, using the rubric in assessment decreased subjectivity of students' evaluation. Because every student knows the criteria of evaluation, there will be no surprises in marking; students can evaluate themselves. Finally, the teacher realized that assessment could be used as learning. Therefore, according to her, she gained a new learning tool.

\section{The difficulties that faced the teachers and her students in applying the rubric}

The teacher reported that she and her students faced some difficulties in applying the rubric in assessment. These difficulties are:

Lack of experience in applying rubrics in assessment. The teacher stated that lack of experience negatively affected applying the rubric in assessment. According to her, 
assessment by rubrics in general is a new method at her school and majority of schools in Spain. Her students had never used rubrics in mathematics classes or in other classes. In addition, the rubric used in this study is highly demanding. This rubric necessitates the students to follow certain steps in solving any problem and it requires the students to explain everything they write with appropriate mathematical language. The teacher asserted that due to lack of experience in assessing by rubrics, and to the demanding nature of this rubric, she had to put much effort and time in training the students to understand and use the rubric. "The main difficulty is to get used to the method and the time it consumes. One thing is paired with the other, because if they were used since the early primary to use this method, they would use it more easily and they do not take a lot of time in answering any questions”.

Difficulties in the rubric's design. The teacher commented that she and her students faced difficulties in applying the rubric due to the challenging nature of the rubric's design. According to her, the language of the rubric is difficult for students to understand. In addition, the rubric demands much explanation and necessitates using language more than symbols. "This rubric is difficult the students didn't understand it, if we enhanced it by making it shorter and rewrite it in a language that they can understand without a lot of words; it will be easier for them".

Moreover, according to the teacher this rubric is very long for the students; her students are not used to read long exams. "The rubric is very long and the students are not used to read. Its, too long for them to handle".

Applying the rubric in assessment is effort and time consuming. The teacher criticized the effort and time consumed in the rubric's application. As a teacher, she complained of much effort and time needed in preparing a similar rubric for every mathematical subject. "Teachers have to prepare a form, a special rubric for every subject, so it takes more work".

In addition, the teacher criticized the time and effort needed in marking students exam sheets because they contain much explanation and a lot of detail. Moreover, the teacher argued that using the rubric with peer assessment consumed extra time from the teacher to review the students' marking.

On the other hand, the teacher explained that using the rubric requires much effort and time from the students since they had to study the content deeply to understand it, otherwise they will not be able to explain what they are doing easily.

\section{DISCUSSION}

Using the rubric was a new experience for the teacher and her students; the teacher was enthusiastic about applying this method. The students also liked the idea of being part of a project that introduce to them an assessment method used by their peers in USA.

Because assessing with the rubric was new for both the teacher and the students, she faced many difficulties, but on the other hand she discovered many benefits from using this method. The teacher asserted that using the rubric did not only enhance her students learning but also her work as a teacher. According to the teacher, using the rubric in assessment allowed her to check the level of understanding for the entire students every day, and motivate her to find the suitable way to help her students to understand what they are learning. The teacher asserted that using the rubric in assessment had the potential to enhance the students' learning, because it requires a high quality answer from the students. Therefore, subsequently the students had to study more in order to solve the problems according to the rubric. She also added that the explanation part of the rubric is very important as it help the students to understand what they are doing and why; not only to solve the problem mechanically. A good body of literature supports these findings (Cebrián \& Accino, 2009; Cooper \& Gargan, 2009; Goodrich, 1997; Moss et al., 2002; Santero, Flores, \& Gordillo, 2010; Yoshina \& Harada, 2007). 
The findings of this study revealed that using the rubric in assessment made the students active participants in their teaching-learning process. According to Cebrián \& Accino (2009) and Goodrich (1997), using rubrics in assessment helps students to develop a sense of responsibility, specifically if they use rubrics in self and peer assessment. In addition, using rubrics in assessment increases the ability of students to judge a quality performance and facilitates constructive and self-regulated learning (Hafner \& Hafner, 2003; Lara, 2010).

The results of this study also indicated that using the rubric in assessment helped the students to know the expectation of their teacher. Similar finding was reported by Andrade (2005), Andrade et al. (2008), Allen \& Tanner (2006), Cooper \& Gargan (2009); Goodrich (1997), Knight (2006), Zimmerman \& Schunk (2001). According to them, using rubrics in assessment increases students' awareness of learning goals, clarify teacher's expectations, and explain the criteria needed to meet a quality performance.

The teacher and her students faced a difficulty in scoring and correcting the exercises using the rubric, however, they enjoyed correcting their partners' exercises (peer assessment). The teacher commented that the students were serious in assessing each other's work. This was contrary to her fears, that they will over mark their partners. The teacher asserted that peer assessment had a positive effect on her students learning. This finding is agreed up on by Hafner \& Hafner (2003) who argued that the use of rubrics in combination with peer assessment provides an effective teaching and learning strategy. Andrade et al. (2008) also support this finding since they argued that using rubrics in assessment enhances the ability of students to evaluate their and their peers' performance.

The results of this study indicated that this rubric was very long and the students are not used to read many paragraphs in the exam's sheet. Andrade (2005) confirmed that most of the students tend not to read a rubric in its entirety.

The teacher criticized the time and effort needed in applying the rubric in assessment. Similar results were found by Andrade (2005) and Cooper \& Gargan (2009) who asserted that rubrics application in assessment require much time and effort in their construction and application. In addition, students need much explanation and practice before using them. Beatty (2008) also agreed that the main disadvantages of using rubric in assessment is related to the time and precision required to develop a genuinely useful rubric; once constructed they can be reused over and again but require continuous thoughtful review and revision.

\section{Acknowledgements}

Funded in part by the Program MAEC-AECID of the Spanish Ministry of Foreign Affairs and Cooperation for Foreign Nationals. Department of University and Scientific Cooperation.

\section{REFERENCES}

Allen, D. \& Tanner, K. (2006). Rubrics: Tools for making learning goals and evaluation criteria explicit for both teachers and learners. CBE-Life Sciences Education, 5(3), 197-203.

Anderson, R. S. (1998). Why talk about different ways to grade? The shift from traditional assessment to alternative assessment. New directions for Teaching and Learning, 1998(74), 5-16.
Andrade, H. (2005). Teaching with Rubrics: The Good, the Bad, and the Ugly. College Teaching, 53(1), 27-30.

Andrade, H., Du, Y. \& Wang, X. (2008). Putting Rubrics to the Test: The Effect of a Model, Criteria Generation, and Rubric-Referenced Self-Assessment on Elementary School Students' Writing. Educational Measurement: Issues and Practice, 3-13.

Beatty, B. (2008). In Support of scoring Rubric, ITEC 865 E-learning, Erica Rutherford. 
Birgin, O. (2011). Pre-service mathematics teachers' views on the use of portfolios in their education as an alternative assessment method. Educational Research and Reviews, 6(11), 710-721.

Cebrián, M. (2009). Formative and peer-to-peer evaluation using a rubric tool. In A. MéndezVilas, A. Solano, J.A. Mesa \& J. Mesa (Eds.). Research, Reflections and Innovations in Integrating ICT in Education, 60-64. Badajoz, Spain: Formatex. Retrieved November 9, 2012 from http: / /www.formatex.org/micte2009/book/ 60-64.pdf

Cebrián, M. \& Accino, J. (2009). From the ePortfolio to Federation Technologies: The Ágora Virtual ${ }^{\circledR}$ Experience, International Seminars on teaching, research and innovation at University. Retrieved November 9, 2012 from http: / / erubrica.uma.es/wpcontent/uploads/2011/06/eportfolioEng.pdf

Cooper, B. \& Gargan, A. (2009). Rubrics in education: Old term, new meanings. Phi Delta Kappan, 91(1), 54-55.

Corti, L. (1993). Using diaries in social research. Social Research Update, 2, 1-4.

Creswell, W. (2007). Qualitative inquiry \& research design: Choosing among five approaches. London: Sage Publications, Inc.

Dochy, F. (2001). A New Assessment Era: Different Needs, New Challenges. Learning and Instruction, 10(1), 11-20.

Dogan, M. (2011). Student teachers' views about assessment and evaluation methods in mathematics. Educational Research and Reviews, 6(5), 417-431.

Flyvbjerg, B. (2006). Five misunderstandings about case-study research. Qualitative inquiry, 12(2), 219-245.

Frey, J. H., \& Oishi, S. M. (1995). How To Conduct Interviews by Telephone and In Person. The Survey Kit, Volume 4. London: SAGE Publications, Inc.

Goodrich, H. (1997). Understanding Rubrics: The dictionary may define" rubric," but these models provide more clarity. Educational Leadership, 54, 14-17.

Hafner, J., \& Hafner, P. (2003). Quantitative analysis of the rubric as an assessment tool: an empirical study of student peer-group rating. International Journal of Science Education, 25(12), 1509-1528.

Johnsen, S. (1996). What Are Alternative Assessments? Gifted Child Today, 19(4), 1214.
Knight, L. A. (2006). Using rubrics to assess information literacy. Reference Services Review, 34(1), 43-55.

McGatha, M., \& Darcy, P. (2010). Rubrics as Formative Assessment Tools. Mathematics Teaching in the Middle School, 15(6), 328.

Mertler, C. A. (2001). Designing scoring rubrics for your classroom. Practical Assessment, Research \& Evaluation, 7(25), 1-10.

Miles, M. B., \& Huberman, A. M. (1994). Qualitative data analysis: An expanded sourcebook. London: Sage Publications, Inc.

Moss, C. M., Gosnell, K., Brookhart, S. M., \& Haber, J. (2002). Reflective practice: Moving pre-service teachers from "goal seeking" to "goal getting" dispositions. CASTL Technical Report No. 3-02. Retrieved March 2, 2013 from

http: / / www.duq.edu/Documents / castl/_pd f/CASTL\%20Technical\%20Report\%203_02. pdf

Nasri, N., Roslan, S. N., Sekuan, M. I., Bakar, K. A., \& Puteh, S. N. (2010). Teachers' Perception on Alternative Assessment. Procedia-Social and Behavioral Sciences, 7, 37-42.

Pajares, M. F. (1992). Teachers' beliefs and educational research: Cleaning up a messy construct. Review of Educational Research, 62(3), 307-332.

Popham, W. J. (1997). What's wrong-and what's right-with Leadership, 55, 72-75.

Sadler, P. M., \& Good, E. (2006). The impact of self-and peer-grading on student learning. Educational Assessment, 11(1), 131.

Santero, J., Flores, J., Gordillo, J. (2010). El Sistema De Rúbricas: Un Ejemplo Práctico. Las rúbricas de evaluación en el desempeño de competencias: ámbitos de investigación y docencia. International Workshop on "Assessment Rubrics in the Performance of Competences: Research and Teaching Areas".

Lara, S. (2010). El andamiaje en la enseñanza: potencial de las rúbricas y las tutorias. Las rúbricas de evaluación en el desempeño de competencias: ámbitos de investigación y docencia. International Workshop on "Assessment Rubrics in the Performance of Competences: Research and Teaching Areas".

Stevens, D. D., \& Levi, A. J. (2005). Introduction to rubrics: An assessment tool to save grading time, convey effective feedback and promote student learning. Oregon Institute of 
Technology \& American Association for Higher Education.

Stiggins, R. (2005). From formative assessment to assessment for learning: A path to success in standards-based schools. The Phi Delta Kappan, 87(4), 324-328.

Wilson, L.W. 2005. What every teacher needs to know about assessment. 2nd ed. Larchmont,

Yoshina, J., \& Harada, V. (2007). Involving students in learning through rubrics. Library Media Connection, 25(5), 10-14.

Zimmerman, B. J., \& Schunk, D. H. (Eds.). (2001). Self-regulated learning and academic achievement: Theoretical perspectives. Mahwah, NJ: Lawrence Erlbaum Associates.

\section{$\diamond \diamond \diamond$}

Citation Suggestions :

APA : Gallego-Arrufat, M.J. \& Dandis, M. (2014). Rubrics in a secondary mathematics class. Mathematics Education, 9(1), 73-82. 